\title{
Goal pursuit, goal adjustment, and affective well-being following lower limb amputation
}

Laura Coffey ${ }^{1,2}$, Pamela Gallagher ${ }^{1,2}$, Deirdre Desmond ${ }^{2,3}$ and Nicola Ryall ${ }^{4}$

${ }^{1}$ School of Nursing and Human Sciences, Dublin City University, Dublin, Ireland

2Dublin Psychoprosthetics Group, Dublin, Ireland

${ }^{3}$ School of Psychology, National University of Ireland Maynooth, Maynooth, Co. Kildare, Ireland

${ }^{4}$ Department of Rehabilitation Medicine, National Rehabilitation Hospital, Dún Laoghaire, Co. Dublin, Ireland

Word count (exc. figures/tables): 4,436

* Requests for reprints should be addressed to Professor Pamela Gallagher, School of Nursing and Human Sciences, Dublin City University, Dublin 9, Ireland (e-mail:

pamela.gallagher@dcu.ie). 


\begin{abstract}
Objectives. This study examined the relationships between tenacious goal pursuit (TGP), flexible goal adjustment (FGA), and affective well-being in a sample of individuals with lower limb amputations.
\end{abstract}

Design. Cross-sectional, quantitative.

Methods. Ninety-eight patients recently admitted to a primary prosthetic rehabilitation programme completed measures of TGP, FGA, positive affect, and negative affect.

Results. Hierarchical regression analyses revealed that TGP and FGA accounted for a significant proportion of the variance in both positive and negative affect, controlling for sociodemographic and clinical characteristics. TGP was significantly positively associated with positive affect, while FGA was significantly negatively associated with negative affect. Moderated regression analyses indicated that the beneficial effect of FGA on negative affect was strongest at high levels of amputation-related pain intensity, and low levels of TGP.

Discussion. TGP and FGA appear to influence subjective well-being in different ways, with TGP promoting the experience of positive affect and FGA buffering against negative affect. TGP and FGA may prove useful in identifying individuals at risk for poor affective outcomes following lower limb amputation, and represent important targets for intervention in this patient group. 


\section{Introduction}

The loss of a limb is a life-changing event that has a significant impact on a person's day-today existence (Gallagher, Desmond, \& MacLachlan, 2007). Amputation not only incurs permanent physical loss and concomitant functional impairment, but can also give rise to difficulties in other important life domains such as interpersonal relationships (Williams et al., 2004), occupational status (Whyte \& Carroll, 2002), recreational activities (Couture, Caron, \& Desrosiers, 2010), and sexuality (Geertzen, Van Es, \& Dijkstra, 2009). Such pervasive losses and limitations represent a critical adaptational challenge that is likely to pose considerable threat to emotional well-being. Indeed, clinically significant levels of psychological distress are reported by a sizeable minority of patients within two years of their procedure (Horgan \& MacLachlan, 2004), and may continue to be experienced for several years thereafter (Desmond \& MacLachlan, 2006; Singh et al., 2009). Most individuals appear to adjust successfully to their limb loss, however, with many achieving positive change and growth as a result of their experiences (Phelps, Williams, Raichle, Turner, \& Ehde, 2008; Unwin, Kacperek, \& Clarke, 2009).

In recent years, researchers have attempted to identify factors that might account for the diversity observed in psychosocial outcomes among individuals with amputations. In keeping with the broader literature on adjustment to illness and disability (Elliott, Kurylo, \& Rivera, 2002), associations with sociodemographic factors and amputation-related characteristics have been weak or inconsistent (Desmond et al., 2012). Research on psychological correlates of adjustment to amputation has tended to focus on individual traits such as hope (Unwin et al., 2009), dispositional optimism (Dunn, 1996), and self-esteem (Donovan-Hall, Yardley, \& Watts, 2002), and little is known about the cognitive, affective, and behavioural mechanisms underlying this process (Elliott, 2002). Greater understanding of these mechanisms could help to explain how particular psychological traits are related to 
desirable outcomes following amputation, and inform the development of interventions to promote optimal adjustment in this patient group (Dunn, Uswatte, \& Elliott, 2009).

Theories of self-regulation provide a useful framework for exploring the mechanisms underlying the process of psychosocial adjustment to amputation. The term 'self-regulation' has been used to describe a range of theoretical approaches from personality, social, and health psychology, all of which share the assumption that human behaviour is organised around the pursuit of goals, which energise and direct activities, and in doing so, give structure and meaning to people's lives (Austin \& Vancouver, 1996; Carver \& Scheier, 1998; Emmons, 1986). The extent to which individuals are able to achieve their goals is thought to have a significant bearing on psychological well-being. For example, Carver and Scheier's model of self-regulation proposes that negative affect is experienced when one's perceived rate of progress towards his or her goals is slower than desired, whereas positive affect arises when goal progress is faster than expected. Perceived difficulties in goal progress are associated with poorer adjustment among persons with debilitating health conditions such as cancer (Offerman, Schroevers, van der Velden, de Boer, \& Pruyn, 2010), cardiac problems (Boersma, Maes, \& van Elderen, 2005), and visual impairment (Boerner \& Cimarolli, 2005; Boerner \& Wang, 2012; Popivker, Wang, \& Boerner, 2010).

Various theories of adaptive self-regulation have been developed to describe how people manage their goals in response to disruptions in goal attainment (Boerner \& Jopp, 2007; Wrosch, Amir, \& Miller, 2011). The dual-process model of assimilative and accommodative processes (Brandstädter \& Renner, 1990) addresses the dynamics of goal striving across the lifespan and has gained traction in research on adjustment to chronic illness and disability in recent years (Boerner, 2004; Boerner \& Wang, 2012; Darlington et al., 2009; Kranz, Bollinger, \& Nilges, 2010; Schmitz, Saile, \& Nilges, 1996; van Lankveld, van Diemen, \& van Nes, 2011). This conceptual framework delineates two basic modes of 
reducing discrepancies between perceived and desired progress towards goal attainment. The assimilative mode (or tenacious goal pursuit, TGP) comprises active efforts to modify one's current situation or behaviour to fit with one's goals and preferences, such as acquiring relevant knowledge and skills, using compensatory means, or implementing lifestyle changes, and enables the person to maintain a sense of identity and purpose. The assimilative mode is useful in improving or maintaining function and tends to dominate as long as a situation is perceived to be changeable, but is constrained by the availability of internal and external resources such as health, social support, and physical capabilities (Brandtstädter \& Rothermund, 2002). When assimilative efforts become ineffective, the accommodative mode (or flexible goal adjustment, FGA) is activated, in which the individual neutralises goal discrepancies by adjusting goals and preferences to what is feasible given current situational constraints. Accommodative strategies include modifying or relinquishing blocked goals, reappraising emerging losses or limitations, and engaging in downward social comparison.

Continued pursuit of goals that are no longer attainable leads to feelings of helplessness and depression (Carver \& Scheier, 1998). The accommodative mode may thus be more adaptive in circumstances of permanent loss or constraint, as it allows the individual to preserve a sense of continuity, efficacy and personal worth in the face of emerging limitations (Brandstädter, 2006). Indeed, FGA has consistently stronger associations than TGP with indicators of subjective well-being among individuals with chronic illness and disability (Boerner, 2004; Boerner \& Wang, 2012; van Lankveld et al., 2011). The accommodative mode has also been found to buffer against the negative emotional impact of potentially deleterious factors such as increasing age (Rothermund \& Brandtstädter, 2003), negative life events (Bailly, Joulain, Hervé, \& Alaphilippe, 2012), chronic pain (Kranz et al., 2010; Schmitz et al., 1996), and functional impairment, particularly among younger individuals (Boerner, 2004). 
According to the dual-process model, assimilation and accommodation embody independent and antagonistic processes. Indeed, correlations between TGP and FGA have been slightly negative or close to zero in most studies (Brandstädter, 2009), yet both indices show convergent positive associations with indicators of subjective well-being such as reduced depressive symptoms, life satisfaction, optimism, emotional stability and quality of life (Brandstädter \& Renner, 1990), and are related to better psychosocial outcomes among patients with various medical conditions (Boerner, 2004; Darlington et al., 2009; Schmitz et al., 1996; van Lankveld et al., 2011). These modes are not mutually exclusive, and may complement each other during concrete episodes of coping in which a number of adaptive tasks are involved, some requiring assimilative persistence, others accommodative flexibility (Brandtstädter \& Rothermund, 2002).

The physical, social and psychological upheaval caused by amputation is likely to threaten the attainment of valued goals, which may leave individuals vulnerable to negative psychosocial outcomes if they do not regulate their goals in response to these challenges. This offers a pertinent context in which to examine the assimilative and accommodative modes described in the dual-process model, and may help to elucidate the mechanisms underlying the process of adjustment to amputation as well as offer some explanation for the diversity observed in people's emotional responses to this experience. The aim of the present study was thus to examine the relationships between TGP, FGA, and both positive and negative affect in a sample of individuals with lower limb amputations. These outcomes were selected, as previous research on psychosocial adjustment in this population has tended to focus almost exclusively on negative outcomes such as depression and anxiety (Desmond et al., 2012). In order to gain a more complete understanding of how amputation affects the individual, an examination of both positive and negative emotional sequelae is required (Phelps et al., 2008). 
The first objective was to examine whether TGP and FGA accounted for a significant proportion of the variance in positive and negative affect, controlling for sociodemographic (age, gender) and clinical (cause of amputation, time since amputation, average pain intensity) factors. Drawing on the assumptions of this model and previous research, it was hypothesised that both adaptive self-regulatory modes would be positively associated with positive affect and negatively associated with negative affect, with associations being strongest for FGA. The second objective was to investigate if either TGP or FGA moderated the effect of age and pain intensity on affective well-being in this population. Based on theoretical assumptions and previous research, it was hypothesised that FGA, but not TGP, would mitigate the influence of age and pain intensity on these outcomes. Exploratory analyses were also conducted to investigate whether TGP and FGA interacted in their associations with positive and negative affect. It was hypothesised that these variables would be negatively correlated, and that the beneficial effect of FGA on positive and negative affect would be strongest at lower levels of TGP.

\section{Method}

\section{Sample and procedure}

Participants were recruited from two urban hospitals in Ireland providing specialised, multidisciplinary, inpatient rehabilitation programmes following lower limb amputation. Patients aged at least 18 years, with major lower limb amputation (for which inpatient rehabilitation services had not previously been provided), and sufficient spoken English for the demands of the study were eligible to participate. Patients were excluded if they were deemed unsuitable to participate due to a previous or current history of psychiatric morbidity (determined on a case-by-case basis by the rehabilitation team's clinical psychologist), or had 
severe cognitive impairment, as indicated by a score $<18$ on the Mini Mental State Examination (MMSE: Folstein, Folstein, \& McHugh, 1975). Potential participants were identified by the consultant in charge of the programme. These patients were informed about the study and given an information sheet. A researcher revisited those interested in participating to discuss the study and answer any questions before they decided whether or not to take part. One hundred and thirteen patients were eligible to participate during the study period (February 2010 - July 2011). Twelve patients declined and three were discharged early from the programme. The remaining 98 patients consented to participation. The study employed a cross-sectional design; a researcher verbally administered the study questionnaire to participants within the first three weeks of their admission. There were no significant differences between participants and non-participants in terms of age, level, or cause of amputation. Fisher's test revealed a significant difference between the groups in terms of gender distribution $(p=.027)$, the proportion of females in the participant group (19.4\%) was significantly smaller than observed among non-participants (50\%).

Participants ranged in age from 25 to 89 years $(M=62.59, S D=13.20)$. Seventy-nine participants were male $(81 \%)$ and $19(19 \%)$ were female. The majority had primary $(45 \%)$ or secondary (39\%) level education only and had a partner (46\%); the remainder were either single (39\%), separated/divorced (18\%), or widowed (14\%). Thirty nine participants $(40 \%)$ lived alone. The time elapsed since amputation ranged from 6 to 260 weeks $(M=30.32$; median $=20.00 ; S D=36.97)$. Forty seven participants $(48 \%)$ had unilateral below-knee amputation, 43 (44\%) had unilateral above-knee amputations, and eight (8\%) had bilateral amputations. For the majority of participants, the cause of amputation was chronic (i.e., peripheral vascular disease, diabetes mellitus, or cancer) in nature $(79 \%)$. The remaining participants $(21 \%)$ underwent amputation secondary to trauma $(8 \%)$ or other acute causes 
(13\%) e.g., deep vein thrombosis. Over $80 \%$ of participants reported at least one comorbid health condition, the most common being cardiac problems and diabetes.

\section{Measures}

Sociodemographic and clinical data on participants' age, gender, education level, marital status, living situation, level and cause of amputation, presence of co-morbidities, and number of weeks since amputation were recorded. Pain intensity was assessed using a single item from the Brief Pain Inventory (BPI: Cleeland, 1989), which asked participants to rate their average experience of amputation-related pain on a numeric rating scale ranging from 0 ('no pain') to 10 ('pain as bad as you can imagine').

Goal pursuit and goal adjustment were measured using the English version of the Tenacious Goal Pursuit (TGP) and Flexible Goal Adjustment (FGA) scales (Brandstädter \& Renner, 1990). The TGP scale assesses the tendency to persist in pursuing goals in the face of setbacks and obstacles (assimilation). The FGA scale measures readiness to disengage from blocked goals and focus on positive aspects of adverse situations (accommodation). Both scales consist of 15 direct- and reverse-keyed items rated on 5-point Likert scales ranging from 'strongly agree' (0) to 'strongly disagree' (4). Reverse-keyed items were recoded and scores were summed to obtain total scores for each scale; higher scores signify a greater tendency to engage in the self-regulatory mode. The TGP and FGA scales have been used in various patient populations (Boerner, 2004; Darlington et al., 2009; van Lankveld et al., 2011) and have performed satisfactorily in terms of reliability and validity (Brandstädter \& Renner, 1990). In the present study, Cronbach's alpha values of 0.81 and 0.64 were observed for the TGP and FGA scales, respectively. 
Positive and negative affect were assessed using the Positive and Negative Affect Schedule (Watson, Clark, \& Tellegen, 1988). This measure consists of 20 words, ten expressing positive emotions and ten expressing negative emotions. Participants were asked to indicate on a scale ranging from 'very slightly or not at all' (1) to 'extremely' (5) the extent to which they had experienced each emotion in the previous four weeks. Positive and negative items were scored separately to give total positive affect and negative affect scores, with higher scores being indicative of greater affect. The PANAS demonstrates good reliability and validity (Watson et al., 1988), and has been successfully employed in previous research on persons with amputations (Unwin et al., 2009). This measure demonstrated good internal reliability in the present study, Cronbach's alpha values were 0.83 and 0.85 for the positive and negative subscales, respectively.

\section{Statistical analyses}

Analyses were conducted using SPSS version 20 (IBM, 2010). Initial exploration of the data was carried out to check for accuracy, amount and distribution of missing values, presence of univariate outliers, and goodness of fit between variable distributions and the assumptions of multiple regression. Missing values were substituted with the mean of the remaining scale item scores in cases where $<20 \%$ of the data were missing. Negative affect was not normally distributed and was subject to square root transformation to better meet the assumptions of multiple regression analysis. Gender ('male' $=0$, 'female' $=1$ ) and cause of amputation ('chronic' $=0$, 'acute' $=1$ ) were recoded into dichotomous dummy variables. Data were summarised as means and standard deviations for continuous variables, or frequencies and percentages for categorical variables. Bivariate associations between predictor and outcome 
variables were examined firstly using Pearson correlations. Hierarchical multiple regression analyses were then conducted to examine the multivariate relationships between variables. Predictors were entered in the following order: age and gender (step 1); cause of amputation, time since amputation, and average pain intensity (step 2); TGP and FGA (step 3). Output from the multiple regression analyses was examined for normality, linearity, multicollinearity and homoscedasticity; none of the assumptions were violated. Post-hoc estimates of statistical power were computed for these analyses using an online calculator (Soper, 2013).

A series of moderator analyses were performed to determine whether TGP or FGA moderated the influence of age and pain intensity on either positive or negative affect (Aiken \& West, 1991). The interaction between TGP and FGA was also examined for each outcome, in order to explore possible associations between these two self-regulatory modes. In each analysis, the predictor and moderator variables were standardised firstly in order to avoid multicollinearity (Frazier, Tix, \& Barron, 2004), and then multiplied together to form the interaction term. The standardised predictor and moderator variables were entered in the first step, followed by the two-way interaction term in the second step. For three-way interactions, the conditional effects of the three predictor and moderator variables were controlled for in the first step, followed by the three two-way interactions between these variables in the second step. The three-way interaction term was then entered in the third step. All significant interaction effects were plotted at values of one standard deviation above and below the mean for the predictor and moderator variables.

\section{Results}

Table 1 displays mean scores (or percentages for categorical variables), standard deviations, and intercorrelations for all study variables. With regard to sociodemographic and clinical 
predictors, being younger, female, having an acute cause of amputation, and experiencing higher pain intensity on average were significantly associated with greater negative affect, while correlations between these variables and positive affect were non-significant. Both TGP and FGA were positively associated with positive affect at the bivariate level, as hypothesised. Negative affect was negatively correlated with FGA, but its association with TGP was non-significant. Contrary to our hypothesis, a significant positive correlation was observed between TGP and FGA, with higher scores on one mode being associated with higher scores on the other.

$$
* * * \text { insert Table } 1 \text { here*** }
$$

Results from the hierarchical regression analyses predicting positive and negative affect are presented in Table 2. Post-hoc statistical power for these analyses was estimated at 0.96 for positive affect and 0.76 for negative affect. TGP and FGA accounted for an additional $15 \%$ of the variance in positive affect once sociodemographic and clinical variables, which did not contribute significantly to the prediction of this outcome, had been controlled for. TGP emerged as the only significant predictor of positive affect. In partial support of our hypothesis, participants who engaged in TGP to a greater extent experienced higher levels of positive affect. The two adaptive self-regulatory modes together explained $7 \%$ of the variance in negative affect, over and above sociodemographic (13\%) and clinical (5\%) characteristics; FGA was the only significant predictor of this outcome. Participants who had a greater tendency to use FGA as an adaptive self-regulatory mode experienced lower negative affect, thus partially supporting our hypothesis.

\footnotetext{
***insert Table 2 here***
} 
A series of moderated regression analyses examined whether TGP and FGA moderated the influence of age or pain intensity on affective well-being (see Table 3). The effect of the two-way interaction between pain intensity and FGA was significant for negative affect, accounting for $7 \%$ of the variance in this outcome, in addition to the $21 \%$ of variance explained by the conditional effects of pain intensity and FGA. Figure 1 displays a plot of the interaction; as hypothesised, FGA buffered against negative affect; its beneficial effect was strongest at high levels of pain intensity.

***insert Table 3 here***

$* * *$ insert Figure 1 here $* * *$

Moderated regression analyses were also carried out to explore the effect of a two-way interaction between TGP and FGA on positive and negative affect (see Table 3). The interaction term was significant for negative affect, and explained an additional $3 \%$ of the variance in this outcome along with the $16 \%$ accounted for by the conditional effects of these adaptive self-regulatory modes. A plot of the interaction revealed that FGA had the greatest protective influence against negative affect at low levels of TGP, as hypothesised (see Figure 2). Finally, exploratory moderated regression analyses were conducted to examine the influence of pain intensity $x$ TGP x FGA and pain intensity $x$ age $x$ FGA three-way interactions on negative affect. The effect of the three-way interaction term on negative affect was not significant in either case, however.

***insert Figure 2 here*** 


\section{Discussion}

The purpose of the present study was to apply the dual-process model of assimilative and accommodative processes (Brandstädter \& Renner, 1990) to the experience of psychosocial adjustment to lower limb amputation. As hypothesised, TGP and FGA together accounted for a significant proportion of the variance in both positive and negative affect, controlling for sociodemographic and clinical factors. This observation is in keeping with previous studies of adjustment to chronic illness and disability in which both assimilative tenacity and accommodative flexibility have been implicated (Boerner, 2004; Boerner \& Wang, 2012; Darlington et al., 2009; Heyl, Wahl, \& Mollenkopf, 2007; van Lankveld et al., 2011). Contrary to our hypotheses, however, although both TGP and FGA were positively associated with positive affect at the bivariate level, TGP was the only independent predictor of positive affect to emerge, with greater assimilative tenacity being associated with higher levels of positive affect. In addition, FGA, but not TGP, was negatively correlated with negative affect, and was the sole independent predictor of this outcome, with greater accommodative flexibility being associated with lower levels of negative affect.

To the authors' knowledge, only one previous study of assimilative and accommodative processes in the context of chronic illness and disability has included positive and negative affect as outcomes. Heyl and colleagues (2007) observed a similar pattern of relationships in a sample of 751 older adults with age-related visual decline living in the community, with TGP predicting positive affect and FGA predicting negative affect. Together, these observations clarify further the dual-process model's assumption that TGP and FGA have independent yet complementary roles in enhancing subjective well-being during concrete coping episodes by indicating that they each influence different elements of 
this construct, with assimilative tenacity promoting positive affect and accommodative flexibility buffering against negative affect. The pattern of findings observed in the present study also fits in with Carver and Scheier's model of self-regulation, as continued striving towards goals (i.e., TGP) is likely to speed up progress towards the attainment of valued goals, resulting in the experience of positive affect, whereas being able to disengage from or adjust one's goals in response to emerging losses and limitations (i.e., FGA) is likely to buffer against the negative affect associated with disruptions in goal attainment (Carver $\&$ Scheier, 1998).

Moderated regression analyses found that FGA buffered against the impact of amputation-related pain intensity on negative affect, with its beneficial effect being strongest at high levels of pain intensity. This is in keeping with previous studies of individuals with chronic pain (Kranz et al., 2010; Schmitz et al., 1996), and provides support for the dualprocess model's assumption that having a greater tendency towards accommodative flexibility protects against the negative consequences of goal failure by allowing the person to disengage from or adjust his or her goals in response to current constraints.

In contrast to the dual-process model's assumption that assimilative and accommodative modes represent independent and antagonistic processes, a significant positive correlation was observed between TGP and FGA, indicating that individuals who were tenacious in their pursuit of goals were also more inclined to flexibly adjust their goals where appropriate. A similar association was observed in a recent study of individuals with acquired visual impairment (Boerner \& Wang, 2012). These findings indicate that both tendencies may operate simultaneously when an individual is faced with non-normative problems such as chronic illness or disability that pose a number of adaptive dilemmas requiring different responses (Brandstädter, 2009). Moderated regression analyses provided further clarification of the relationship between these two adaptive self-regulatory modes, 
however, indicating that the buffering influence of FGA on negative affect was strongest when TGP was low. Indeed, Heyl and colleagues (2007) observed a similar pattern of associations between TGP and FGA in relation to negative affect, providing support for the assumption that these modes have an antagonistic relationship, at least with regard to negative affect. These findings also point to the primacy of accommodative flexibility as an adaptive self-regulatory mechanism in responding to situations involving irrevocable loss and limitation. Conflicting findings have been observed in a recently published ten-year longitudinal study of an aging population, however, with individuals who scored high on both tendencies experiencing the largest decreases in depressive symptoms, hostility, and physical ill-health (Kelly, Wood, \& Mansell, 2013). Further research is thus required to clarify the nature of the interaction between these two modes, in both normative and non-normative situations.

Overall, the results of the present study indicate that the dual-process model provides a useful framework for examining psychosocial adjustment to amputation that might help to elucidate the mechanisms underlying this process and explain the diversity observed in people's affective responses. The assimilative and accommodative modes described in this model may offer some insight into how particular psychological traits are associated with subjective well-being in this population, the so-called 'black box' of research on adjustment to chronic illness and disability (Elliott, 2002). For example, previous research has found that individuals high in dispositional optimism demonstrate great sensitivity to the nature of stressful situations through their responses, using strategies such as planning or seeking instrumental social support as long as a stressor appears to be within their control, but switching to strategies such as positive reframing and acceptance when faced with an uncontrollable stressor such as a traumatic health event (Aspinwall \& Richter, 1999; Nes \& Segerstrom, 2006), which implies that assimilative and accommodative processes may play 
some part in the beneficial impact of optimism on psychosocial outcomes. It would be interesting to explore the interactions between these adaptive self-regulatory modes and psychological traits such as optimism in future research.

A major strength of this model, and theories of self-regulation more generally, is the capacity to account for the experience of both positive and negative affect following a significant life event such as amputation (Boerner \& Jopp, 2007; Carver \& Scheier, 1998). The present study lends further support to the argument that positive and negative affect are independent constructs rather than opposite poles of a single dimension (Diener \& Emmons, 1984; Watson et al., 1988), and demonstrates the importance of assessing both facets of affective well-being in research on adjustment to illness and disability. A further strength of the dual-process model is the universality of its constructs, as the adaptive self-regulatory modes it describes are applicable to any life situations in which change is encountered. Indeed, the relevance of assimilative and accommodative processes in adapting to adverse circumstances has been independently acknowledged by a number of authors in recent years, who have incorporated these self-regulatory modes into their own frameworks for describing adaptation and resilience (Brands, Wade, Stapert, \& van Heugten, 2012; Crombez, Eccleston, Van Damme, Vlaeyen, \& Karoly, 2012; Frazier, Newman, \& Jaccard, 2007; Park, 2010). The dual-process model and its focus on the individual's goals may be particularly suited to the rehabilitation context, as it could easily be incorporated into the goal-oriented approach that is already common practice in rehabilitation settings (Brands et al., 2012). Studies conducted in different rehabilitation patient groups have found that disability-related goal interference is associated with poorer adjustment outcomes (Boerner \& Cimarolli, 2005; Conrad, Doering, Rief, \& Exner, 2010). Sivaraman Nair (2003) suggests that coping with the loss of valued goals and refocusing on more attainable goals are essential for rehabilitation to be a success. The dual-process model may thus serve as a useful foundation for the 
development of interventions that focus on identifying goals that are still feasible and strengthening strategies to attain them while providing support in modifying or dissolving commitment to goals that are no longer achievable. Some have argued that such an approach should become an integral part of the rehabilitation process (Boerner \& Wang, 2012; Popivker et al., 2010; Sivaraman Nair, 2003). Indeed, a recently developed cognitivebehavioural therapy intervention for rheumatic diseases, which is currently undergoing formal evaluation, was theoretically grounded in the dual-process model and included sessions specifically targeted at enhancing both assimilative and accommodative coping responses (Vriezekolk et al., 2012). Existing interventions such as Acceptance and Commitment Therapy (ACT: Hayes, Strosahl, \& Wilson, 1999), which aims to facilitate individuals to live a purposeful and meaningful life by focusing on and engaging with their goals and values, while taking into account the limitations imposed by their situational constraints (Kangas \& McDonald, 2011), may also prove effective in enhancing the use of these adaptive selfregulatory modes. Future research should investigate the efficacy of such interventions in enhancing TGP and FGA, and, concomitantly, psychosocial adjustment, following lower limb amputation and other forms of acquired disability.

There are certain limitations that should be considered when interpreting the results of this study. Firstly, the findings were cross-sectional in nature, precluding the inference of causality. Indeed, the relationships observed may have been bi-directional in nature; for example, experiencing less positive affect may have reduced motivation to employ assimilative processes and persist in striving towards goals, while experiencing greater negative affect may have triggered self-protective, accommodative processes. Longitudinal explorations of the associations between self-regulatory constructs and psychosocial outcomes in this population are required to shed more light on the causal direction of these relationships. The representativeness of the sample in the present study may also pose some 
limitations with regard to the generalizability of findings. Patients who participated had been admitted to a prosthetic rehabilitation programme, and are thus likely to represent a healthier and more able-bodied sector of this patient group. There were also significantly fewer females among participants than non-participants, suggesting that women may have been underrepresented in the sample. The ratio of males to females is comparable to previous studies of individuals with lower limb amputations, however (Phelps et al., 2008; Unwin et al., 2009). The use of positive and negative affect as the only indices of subjective well-being represents another limitation of the present study. Subjective well-being is a broad concept that also encompasses satisfaction in specific life domains and global life satisfaction (Diener, Suh, Lucas, \& Smith, 1999). Future studies could be enhanced by including a measure of life satisfaction, which forms a separate factor from the two types of affect (Lucas, Diener, \& Suh, 1996) and represents a more enduring aspect of subjective well-being that may have different associations with assimilative and accommodative modes. Indeed, previous research has indicated that in contrast to positive affect, life satisfaction is related to accommodative rather than assimilative processes (Boerner \& Wang, 2012). Future research may also benefit from including a measure of functional disability, as previous research has indicated that FGA appears to buffer its impact on subjective well-being, particularly among younger individuals with acquired physical impairment (Boerner, 2004).

In conclusion, the findings of the present study support the utility of the dual-process model in describing psychosocial adjustment to lower limb amputation, with TGP and FGA accounting for a significant amount of the variance in positive and negative affect, controlling for sociodemographic and clinical variables. Assimilative and accommodative modes of adaptive self-regulation appear to complement each other in the adjustment process, with TGP promoting positive affect and FGA buffering against negative affect. Both assimilative 
tenacity and accommodative flexibility represent potentially important targets for interventions that facilitate adjustment to limb loss. 


\section{References}

Aiken, L. S., \& West, S. G. (1991). Multiple regression: Testing and interpreting interactions. Thousand Oaks, CA: Sage.

Aspinwall, L. G., \& Richter, L. (1999). Optimism and self-mastery predict more rapid disengagement from unsolvable tasks in the presence of alternatives. Motivation and Emotion, 23(3), 221-245. doi: 10.1023/A:1021367331817

Austin, J. T., \& Vancouver, J. B. (1996). Goal constructs in psychology: Structure, process, and content. Psychological Bulletin, 120, 338-375. doi: 10.1037/0033-2909.120.3.338

Bailly, N., Joulain, M., Hervé, C., \& Alaphilippe, D. (2012). Coping with negative life events in old age: The role of tenacious goal pursuit and flexible goal adjustment. Aging and Mental Health, 16(4), 431-437. doi: 10.1080/13607863.2011.630374

Boerner, K. (2004). Adaptation to disability among middle-aged and older adults: The role of assimilative and accommodative coping. Journals of Gerontology Series B: Psychological Sciences and Social Sciences, 59(1), 35-42. doi: 10.1093/geronb/59.1.P35

Boerner, K., \& Cimarolli, V. R. (2005). Optimizing rehabilitation for adults with visual impairment: Attention to life goals and their links to well-being. Clinical Rehabilitation, 19(7), 790-798. doi: 10.1191/0269215505cr893oa

Boerner, K., \& Wang, S. (2012). Goals with limited vision: A qualitative study of coping with vision-related goal interference in midlife. Clinical Rehabilitation, 26(1), 81-93. doi: $10.1177 / 0269215511407219$ 
Boerner, K., \& Jopp, D. (2007). Improvement/maintenance and reorientation as central features of coping with major life change and loss: Contributions of three life-span theories. Human Development, 50(4), 171-195. doi: 10.1159/000103358

Boerner, K., \& Wang, S. (2012). Targets for rehabilitation: An evidence base for adaptive coping with visual disability. Rehabilitation Psychology, 57(4), 320-327. doi: $10.1037 / \mathrm{a} 0030787$

Boersma, S. N., Maes, S., \& van Elderen, T. (2005). Goal disturbance predicts health-related quality of life and depression 4 months after myocardial infarction. British Journal of Health Psychology, 10(4), 615-630. doi: 10.1348/135910705X52525

Brands, I. M. H., Wade, D. T., Stapert, S. Z., \& van Heugten, C. M. (2012). The adaptation process following acute onset disability: An interactive two-dimensional approach applied to acquired brain injury. Clinical Rehabilitation, 26(9), 840-852. doi: $10.1177 / 0269215511432018$

Brandstädter, J. (2006). Adaptive resources in later life: Tenacious goal pursuit and flexible goal adjustment. In M. Csikszentmihalyi, \& I. S. Csikszentmihalyi (Eds.), A life worth living: Contributions to positive psychology (pp. 143-164). London: Oxford University Press.

Brandstädter, J. (2009). Goal pursuit and goal adjustment: Self-regulation and intentional selfdevelopment in changing developmental contexts. Advances in Life Course Research, 14, 52-62. doi: 10.1016/j.alcr.2009.03.002 
Brandstädter, J., \& Renner, G. (1990). Tenacious goal pursuit and flexible goal adjustment: Age-related analysis of assimilative and accommodative strategies of coping. Psychology of Aging, 5, 58-67. doi: 10.1037/0882-7974.5.1.58

Brandtstädter, J., \& Rothermund, K. (2002). The life-course dynamics of goal pursuit and goal adjustment: A two-process framework. Developmental Review, 22(1), 117-150. doi:

\section{$\underline{10.1006 / \text { drev.2001.0539 }}$}

Carver, C. S., \& Scheier, M. F. (1998). On the self-regulation of behavior. Cambridge: Cambridge University Press.

Cleeland, C. S. (1989). Measurement of pain by subjective report. In C. R. Chapman, \& J. D. Loeser (Eds.), Advances in pain research and therapy, volume 12: Issues in pain measurement (pp. 391-403). New York: Raven Press.

Conrad, N., Doering, B. K., Rief, W., \& Exner, C. (2010). Looking beyond the importance of life goals. The personal goal model of subjective well-being in neuropsychological rehabilitation. Clinical Rehabilitation, 24(5), 431-443. doi: 10.1177/0269215509358930

Couture, M., Caron, C. D., \& Desrosiers, J. (2010). Leisure activities following a lower limb amputation. Disability \& Rehabilitation, 32(1), 57-64. doi: 10.3109/09638280902998797

Crombez, G., Eccleston, C., Van Damme, S., Vlaeyen, J. W. S., \& Karoly, P. (2012). Fearavoidance model of chronic pain: The next generation. Clinical Journal of Pain, 28(6), 475-483. doi: 10.1097/AJP.0b013e3182385392

Darlington, A. S. E., Dippel, D. W. J., Ribbers, G. M., van Balen, R., Passchier, J., \& Busschbach, J. J. V. (2009). A prospective study on coping strategies and quality of life in patients after stroke, assessing prognostic relationships and estimates of cost- 
effectiveness. Journal of Rehabilitation Medicine, 41(4), 237-241. doi:

$10.2340 / 16501977-0313$

Desmond, D. M., Coffey, L., Gallagher, P., MacLachlan, M., Wegener, S. T., \& O'Keeffe, F. (2012). Limb amputation. In P. Kennedy (Ed.), The Oxford handbook of rehabilitation psychology (pp. 351-367). New York: Oxford University Press.

Desmond, D. M., \& MacLachlan, M. (2006). Affective distress and amputation-related pain among older men with long-term, traumatic limb amputations. Journal of Pain and Symptom Management, 31(4), 362-368. doi: 10.1016/j.jpainsymman.2005.08.014

Diener, E., \& Emmons, R. A. (1984). The independence of positive and negative affect. Journal of Personality and Social Psychology; Journal of Personality and Social Psychology, 47(5), 1105-1117. doi: 10.1037//0022-3514.47.5.1105

Diener, E., Suh, E. M., Lucas, R. E., \& Smith, H. L. (1999). Subjective well-being: Three decades of progress. Psychological Bulletin, 125(2), 276-302. doi: 10.1037/00332909.125.2.276

Donovan-Hall, M. K., Yardley, L., \& Watts, R. J. (2002). Engagement in activities revealing the body and psychosocial adjustment in adults with a trans-tibial prosthesis. Prosthetics and Orthotics International, 26(1), 15-22. doi: 10.1080/03093640208726617

Dunn, D. S., Uswatte, G., \& Elliott, T. R. (2009). Happiness, resilience, and positive growth following physical disability: Issues for understanding, research, and therapeutic intervention. In J. Shane, \& C. R. Snyder (Eds.), (2nd ed., pp. 651-664). New York, NY: Oxford University Press. 
Dunn, D. S. (1996). Well-being following amputation: Salutary effects of positive meaning, optimism, and control. Rehabilitation Psychology, 41(4), 285-302. doi: 10.1037/00905550.41 .4 .285

Elliott, T. R. (2002). Defining our common ground to reach new horizons. Rehabilitation Psychology, 47(2), 131-143. doi: 10.1037/0090-5550.47.2.131

Elliott, T. R., Kurylo, M., \& Rivera, P. (2002). Positive growth following acquired physical disability. In C. R. Snyder, \& S. L. Lopez (Eds.), Handbook of positive psychology (pp. 687-699). New York, NY: Oxford University Press.

Emmons, R. A. (1986). Personal strivings: An approach to personality and subjective wellbeing. Journal of Personality and Social Psychology, 51(5), 1058-1068. doi: $10.1037 / 0022-3514.51 .5 .1058$

Folstein, M. F., Folstein, S. E., \& McHugh, P. R. (1975). "Mini-mental state": A practical method for grading the cognitive state of patients for the clinician. Journal of Psychiatric Research, 12(3), 189-198.

Frazier, P. A., Tix, A. P., \& Barron, K. E. (2004). Testing moderator and mediator effects in counseling psychology research. Journal of Counseling Psychology, 51(1), 115-134. doi: $10.1037 / 0022-0167.51 .1 .115$

Frazier, L. D., Newman, F. L., \& Jaccard, J. (2007). Psychosocial outcomes in later life: A multivariate model. Psychology and Aging, 22(4), 676-689. doi: 10.1037/08827974.22 .4 .676

Gallagher, P., Desmond, D., \& MacLachlan, M. (2007). Psychoprosthetics. London: Springer. 
Geertzen, J. H. B., Van Es, C. G., \& Dijkstra, P. U. (2009). Sexuality and amputation: A systematic literature review. Disability \& Rehabilitation, 31(7), 522-527. doi: $10.1080 / 09638280802240589$

Hayes, S. C., Strosahl, K., \& Wilson, K. G. (1999). Acceptance and Commitment Therapy: An experiential approach to behavior change. New York: Guilford Press.

Heyl, V., Wahl, H., \& Mollenkopf, H. (2007). Affective well-being in old age: The role of tenacious goal pursuit and flexible goal adjustment. European Psychologist, 12(2), 119129. doi: 10.1027/1016-9040.12.2.119

Horgan, O., \& MacLachlan, M. (2004). Psychosocial adjustment to lower-limb amputation: A review. Disability \& Rehabilitation, 26(14), 837-850. doi:

\section{$10.1080 / 09638280410001708869$}

Kangas, M., \& McDonald, S. (2011). Is it time to act? The potential of Acceptance and Commitment Therapy for psychological problems following acquired brain injury. Neuropsychological Rehabilitation, 21(2), 250-276. doi: 10.1080/09602011.2010.540920

Kelly, R. E., Wood, A. M., \& Mansell, W. (2013). Flexible and tenacious goal pursuit lead to improving well-being in an aging population: a ten-year cohort study. International Psychogeriatrics, 25(1), 16-24. doi: 10.1017/S1041610212001391

Kranz, D., Bollinger, A., \& Nilges, P. (2010). Chronic pain acceptance and affective wellbeing: A coping perspective. European Journal of Pain, 14(10), 1021-1025. doi: 10.1016/j.ejpain.2010.03.010 
Lucas, R. E., Diener, E., \& Suh, E. (1996). Discriminant validity of well-being measures. Journal of Personality and Social Psychology, 71(3), 616-628. doi: 10.1037/00223514.71.3.616

Nes, L. S., \& Segerstrom, S. C. (2006). Dispositional optimism and coping: A meta-analytic review. Personality and Social Psychology Review, 10(3), 235-251. doi: 10.1207/s15327957pspr1003_3

Offerman, M. P. J., Schroevers, M. J., van der Velden, L. A., de Boer, M. F., \& Pruyn, J. F. A. (2010). Goal processes \& self-efficacy related to psychological distress in head \& neck cancer patients and their partners. European Journal of Oncology Nursing, 14(3), 231-237. doi: 10.1016/j.ejon.2010.01.022

Park, C. L. (2010). Making sense of the meaning literature: An integrative review of meaning making and its effects on adjustment to stressful life events. Psychological Bulletin, 136(2), 257-301. doi: 10.1037/a0018301

Phelps, L. F., Williams, R. M., Raichle, K. A., Turner, A. P., \& Ehde, D. M. (2008). The importance of cognitive processing to adjustment in the 1st year following amputation. Rehabilitation Psychology, 53(1), 28-38. doi: 10.1037/0090-5550.53.1.28

Popivker, L., Wang, S., \& Boerner, K. (2010). Eyes on the prize: Life goals in the context of visual disability in midlife. Clinical Rehabilitation, 24(12), 1127-1135. doi: $10.1177 / 0269215510371421$

Rothermund, K., \& Brandtstädter, J. (2003). Depression in later life: Cross-sequential patterns and possible determinants. Psychology and Aging, 18(1), 80-90. doi: 10.1037/08827974.18.1.80 
Schmitz, U., Saile, H., \& Nilges, P. (1996). Coping with chronic pain: Flexible goal adjustment as an interactive buffer against pain-related distress. Pain, 67, 41-51. doi: 10.1016/0304-3959(96)03108-9

Singh, R., Ripley, D., Pentland, B., Todd, I., Hunter, J., Hutton, L., et al. (2009). Depression and anxiety symptoms after lower limb amputation: The rise and fall. Clinical Rehabilitation, 23(3), 281-286. doi: 10.1177/0269215508094710

Sivaraman Nair, K. P. (2003). Life goals: The concept and its relevance to rehabilitation. Clinical Rehabilitation, 17(2), 192-202. doi: 10.1191/0269215503cr599oa

Soper, D.S. (2013) Post-hoc Statistical Power Calculator for Hierarchical Multiple Regression (Computer software). Retrieved 27 March 2013, from http://www.danielsoper.com/statcalc

Unwin, J., Kacperek, L., \& Clarke, C. (2009). A prospective study of positive adjustment to lower limb amputation. Clinical Rehabilitation, 23(11), 1044-1050. doi: $10.1177 / 0269215509339001$

van Lankveld, W., van Diemen, T., \& van Nes, I. (2011). Coping with spinal cord injury: Tenacious goal pursuit and flexible goal adjustment. Journal of Rehabilitation Medicine, 43(10), 923-929. doi: 10.2340/16501977-0870

Vriezekolk, J. E., Geenen, R., van den Ende, C. H. M., Slot, H., van Lankveld, W. G. J. M., \& van Helmond, T. (2012). Behavior change, acceptance, and coping flexibility in highly distressed patients with rheumatic diseases: Feasibility of a cognitive-behavioral therapy in multimodal rehabilitation. Patient Education and Counseling, 87(2), 171-177. doi: 10.1016/j.pec.2011.09.001 
Watson, D., Clark, L. A., \& Tellegen, A. (1988). Development and validation of brief measures of positive and negative affect: The PANAS scales. Journal of Personality and Social Psychology, 54(6), 1063-1070. doi: 10.1037/0022-3514.54.6.1063

Whyte, A. S., \& Carroll, L. J. (2002). A preliminary examination of the relationship between employment, pain and disability in an amputee population. Disability \& Rehabilitation, 24(9), 462-470. doi: 10.1080/09638280110105213

Williams, R. M., Ehde, D. M., Smiths, D. G., Czerniecki, J. M., Hoffman, A. J., \& Robinson, L. R. (2004). A two-year longitudinal study of social support following amputation. Disability \& Rehabilitation, 26(14), 862-874. doi: 10.1080/09638280410001708878

Wrosch, C., Amir, E., \& Miller, G. E. (2011). Goal adjustment capacities, coping, and subjective well-being: The sample case of caregiving for a family member with mental illness. Journal of Personality and Social Psychology, 100(5), 934-946. doi: $10.1037 / \mathrm{a} 0022873$ 
Table 1. Descriptive statistics and intercorrelations for study variables.

\begin{tabular}{|c|c|c|c|c|c|c|c|c|c|c|c|}
\hline & Variable & $M($ or $\%)$ & $S D$ & 1 & 2 & 3 & 4 & 5 & 6 & 7 & 8 \\
\hline 1. & Age & 62.59 & 13.20 & - & & & & & & & \\
\hline 2. & Gender (female) & $20 \%$ & - & -0.01 & - & & & & & & \\
\hline 3. & Cause of amputation (acute) & $21 \%$ & - & $-0.64 * *$ & 0.11 & - & & & & & \\
\hline 4. & Time since amputation & 30.32 & 36.97 & -0.14 & -0.08 & 0.08 & - & & & & \\
\hline 5. & Average pain intensity & 2.59 & 2.34 & $-0.26^{* *}$ & 0.17 & $0.26^{* *}$ & 0.20 & - & & & \\
\hline 6. & TGP & 33.23 & 7.51 & $-0.28 * *$ & -0.17 & $0.26 * *$ & -0.05 & -0.07 & - & & \\
\hline 7. & FGA & 38.88 & 5.05 & $0.23^{*}$ & $-0.22 *$ & $-0.25^{*}$ & -0.12 & $-0.22 *$ & $0.34 * *$ & - & \\
\hline 8. & Positive affect & 35.87 & 7.68 & -0.09 & 0.01 & 0.06 & -0.16 & -0.08 & $0.36^{* *}$ & $0.28 * *$ & - \\
\hline 9. & Negative affect & 16.54 & 6.84 & $-0.23^{*}$ & $0.28 * *$ & $0.26^{*}$ & 0.06 & $0.30 * *$ & -0.09 & $-0.40 * *$ & 0.02 \\
\hline
\end{tabular}

Note: The mean and standard deviation presented for negative affect were calculated prior to transformation.

$* p \leq .05 ; * * \leq .01$ 
Table 2. Results of hierarchical regression analyses for positive and negative affect

\begin{tabular}{|c|c|c|c|c|c|c|c|c|}
\hline \multirow[t]{2}{*}{ Variable } & \multicolumn{4}{|c|}{ Positive affect } & \multicolumn{4}{|c|}{ Negative affect } \\
\hline & $B$ & $S E B$ & $\beta$ & $\Delta R^{2}$ & $B$ & $S E B$ & $\beta$ & $\Delta R^{2}$ \\
\hline Step 1 & & & & .009 & & & & $.130 * * *$ \\
\hline Age & -0.06 & 0.08 & -0.10 & & -0.01 & 0.01 & -0.07 & \\
\hline Gender & 1.93 & 1.90 & 0.10 & & 0.34 & 0.19 & 0.17 & \\
\hline Step 2 & & & & .036 & & & & .048 \\
\hline Cause of amputation & -0.48 & 2.39 & -0.03 & & 0.15 & 0.24 & 0.08 & \\
\hline Time since amputation & -0.03 & 0.02 & -0.12 & & 0.01 & 0.01 & -0.01 & \\
\hline Pain intensity & -0.08 & 0.34 & -0.03 & & 0.06 & 0.03 & 0.17 & \\
\hline Step 3 & & & & $.145^{* * *}$ & & & & $.072 *$ \\
\hline TGP & 0.28 & 0.12 & $0.28 *$ & & 0.01 & 0.01 & 0.01 & \\
\hline \multirow[t]{3}{*}{ FGA } & 0.32 & 0.17 & $0.21 \dagger$ & & -0.05 & 0.02 & $-0.29 * *$ & \\
\hline & \multicolumn{6}{|c|}{ Adj. $R^{2}=.126$} & \multicolumn{2}{|c|}{ Adj. $R^{2}=.19$} \\
\hline & \multicolumn{6}{|c|}{$F(7,90)=3.01^{* *}$} & \multicolumn{2}{|c|}{$F(7,90)=4.28 * * *$} \\
\hline
\end{tabular}

Note: An inverse transformation was performed on perceived social support at Time 1, and scores on this variable should be reversed prior to interpretation. $* p \leq .05 ; * * p \leq .01 ; * * * p \leq .001 ; \dagger p=.06$ 
Table 3. Results of moderated regression analyses of two-way interactions on positive and negative affect

\begin{tabular}{|c|c|c|c|c|}
\hline \multirow[t]{2}{*}{ Variable } & \multicolumn{2}{|c|}{ Positive affect } & \multicolumn{2}{|c|}{ Negative affect } \\
\hline & $\beta$ & $\Delta R^{2}$ & $\beta$ & $\Delta R^{2}$ \\
\hline Step 1 & & $.129 * *$ & & $.082 *$ \\
\hline Age & 0.01 & & $-0.28 * *$ & \\
\hline TGP & $0.38 * * *$ & & -0.16 & \\
\hline Step 2 & & .013 & & .004 \\
\hline Age $x$ TGP & 0.12 & & 0.07 & \\
\hline Step 1 & & $.107 * *$ & & $.180 * * *$ \\
\hline Age & -0.13 & & -0.11 & \\
\hline FGA & $0.35^{* *}$ & & $-0.32 * *$ & \\
\hline Step 2 & & .008 & & .014 \\
\hline Age x FGA & 0.10 & & 0.14 & \\
\hline Step 1 & & $.132 * *$ & & $.093 * *$ \\
\hline Pain intensity & -0.04 & & $0.28 * *$ & \\
\hline TGP & $0.37 * * *$ & & -0.09 & \\
\hline Step 2 & & .005 & & .004 \\
\hline Pain intensity $\mathrm{x}$ TGP & 0.07 & & -0.07 & \\
\hline Step 1 & & $.081 *$ & & $.207 * * *$ \\
\hline Pain intensity & -0.02 & & $0.21 *$ & \\
\hline FGA & $0.29 * *$ & & $-0.34 * * *$ & \\
\hline Step 2 & & .011 & & $.079 * *$ \\
\hline Pain intensity $x$ FGA & -0.11 & & $-0.28 * *$ & \\
\hline Step 1 & & $.159 * * *$ & & $.161 * * *$ \\
\hline TGP & $0.31 * *$ & & 0.01 & \\
\hline FGA & 0.18 & & $-0.40 * * *$ & \\
\hline Step 2 & & .005 & & $.034 *$ \\
\hline TGP $x$ FGA & -0.07 & & $0.19 *$ & \\
\hline
\end{tabular}

$* p \leq .05 ; * * p \leq .01 ; * * * \leq \leq .001$ 


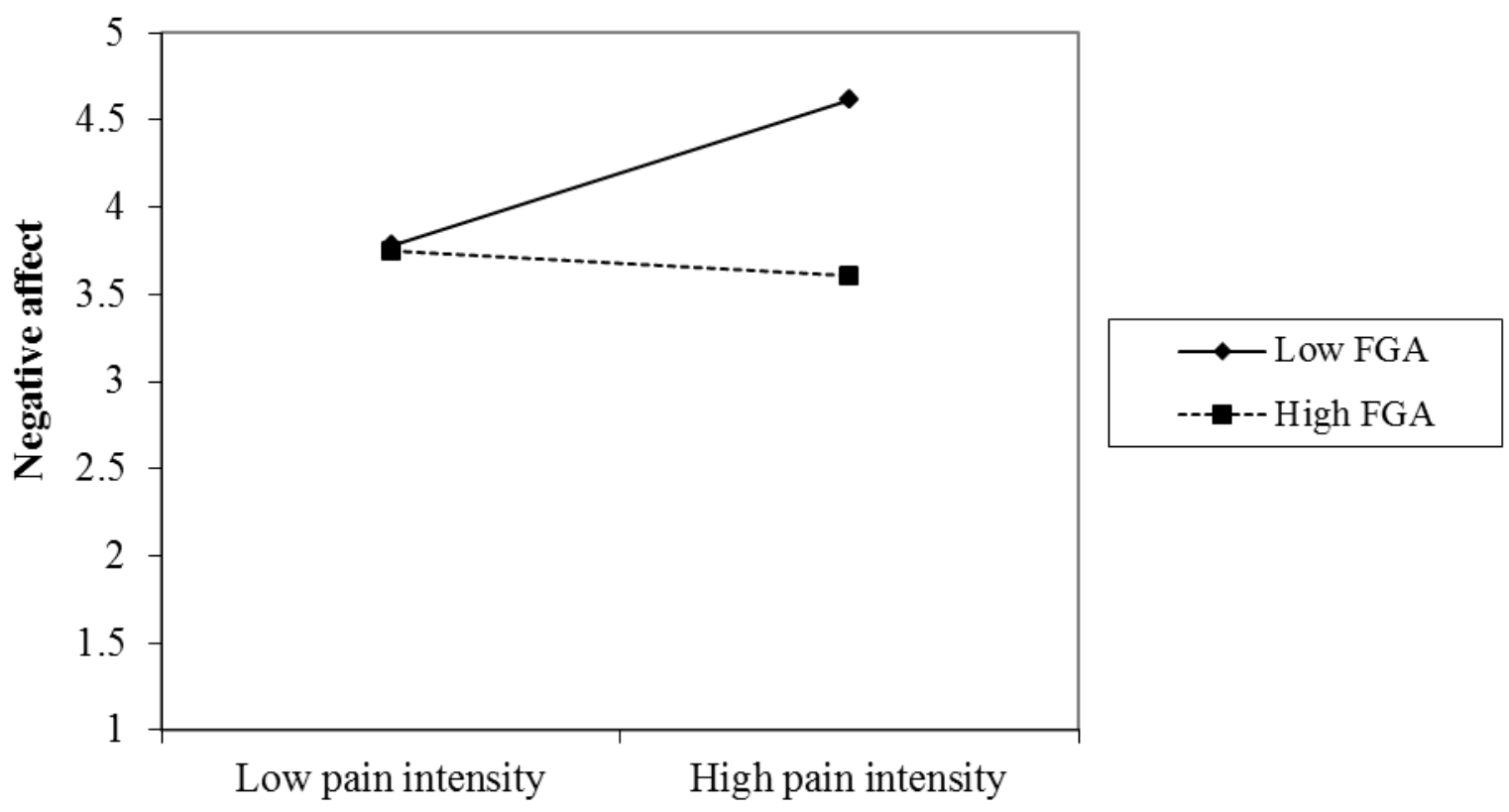

Figure 1. Plot of pain intensity x FGA interaction effect on negative affect 


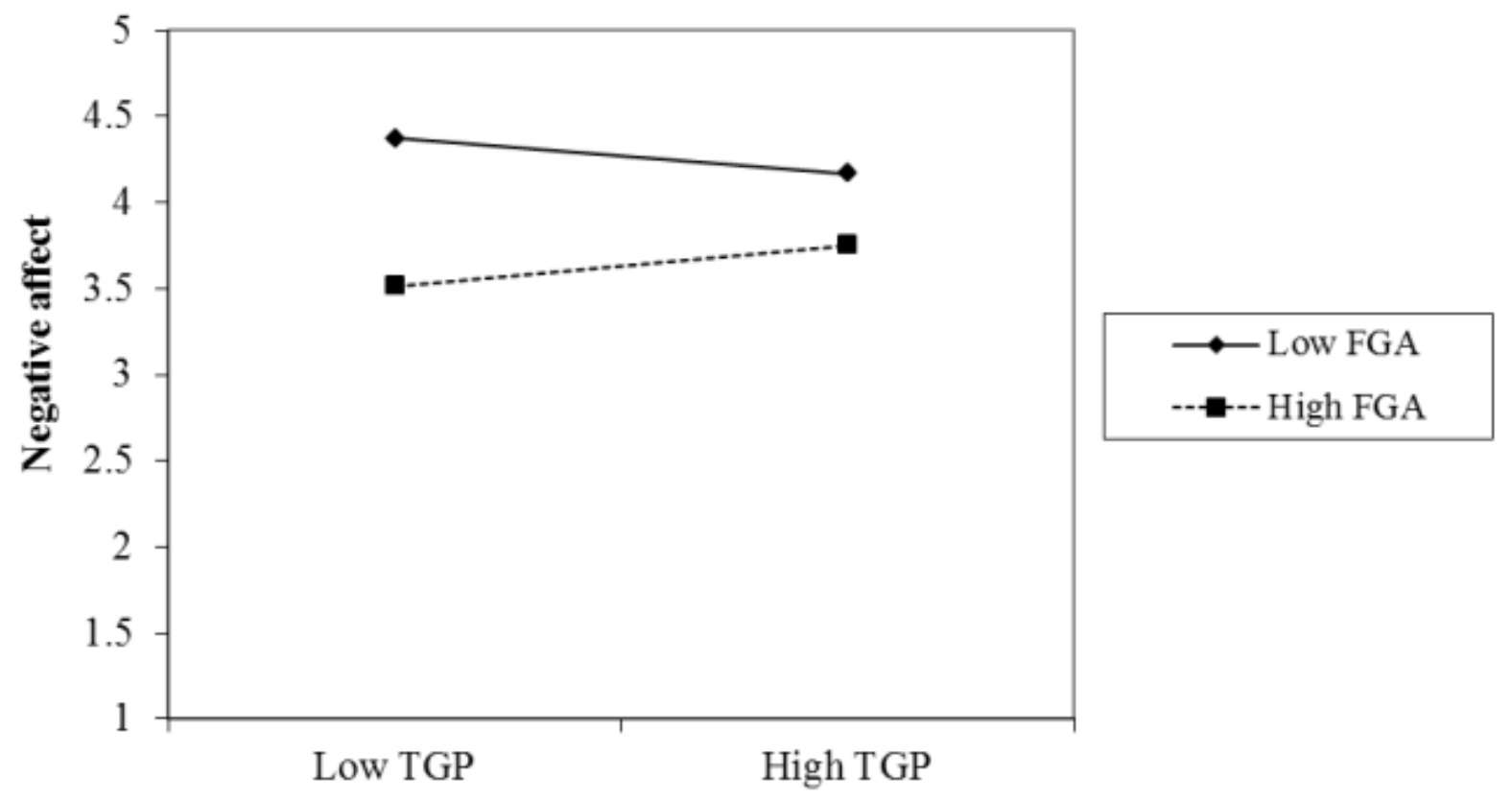

Figure 2. Plot of TGP x FGA interaction effect on negative affect 